\title{
EPILEPSY IS A DISEASE!
}

\author{
WALTER OLESCHKO ARRUDA *
}

SUMMARY - According to the definition of disease, epilepsy shall not be considered neither a symptom nor a syndrome. Epilepsy is a generic term for a group of diseases characterized by seizures. It implies a state quite distinct from health. Therefore it seems worthy to keep epilepsy as such in the International Classification of Diseases (ICD).

KEY WORDS: epilepsy, disease, symptom, syndrome.

\section{Epilepsia é uma doença!}

RESUMO - De acordo com o conceito de doença, epilepsia é uma condição distinta do estado de saúde. Epilepsia é a denominação genérica de um grupo de doenças, as epilepsias. Não é um sintoma/sinal (crises epilépticas), nem tampouco trata-se de uma síndrome, conjunto de sinais/sintomas; ambos são conceitos que integram um conceito maior de doença. Epilepsia como entidade mórbida deve ser mantida como tal na Classificação Internacional das Doenças.

PALAVRAS-CHAVE: epilepsia, doença, sintoma, síndrome.

"The disease is a verictable scourge that leaves its indelible mark upon the victim, often attacking him at an early age, unfitting him for the serious work of life and blighting all the hopes dependent upon him"

B. Sachs, $1892^{2}$

There has been some debate about epilepsy being either a disease, a symptom, or a syndrome ${ }^{1}$.It has been even suggested to exclude epilepsy from the International Classification of Disease. I guess there is not such controversy. Moreover, to consider epilepsy as a symptom and not a disease is probably inaccurate and pointless. Instead of trying to compare different views regarding epilepsy as a disease or not, I will go over some ideas.

Epilepsy shall be considered a DISEASE by definition - "a condition which alters or interferes with the normal state of an organism and is usually characterized by the abnormal functioning of one or more of the host's systems parts or organs; ... a given disease if often manifested by a characteristic set of signs and symptoms; ... Disease is usually distinguished from ... and often from syndrome, a complex of symptoms descriptive of a disorder"2. SYNDROME is an operational concept for a set of signs and symptoms, regardless the etiology, and so, can not be considered a synonym of disease. It is a diagnostic tool.

Epilepsy is a generic term for a group of diseases (individual morbid entities) with different syndromic expressions and etiologies. There are several forms of epilepsy the same way there are

*Neurologista, Unidade de Ciências Neurológicas, Curitiba. Aceite: 1-julho-1994.

Dr. Walter Oleschko Arruda - Rua Gonçalves Dias 713 - 80.240-340 Curitiba PR - Brasil. 
several types of stroke, pneumonia, dementia, cancer and so on. Seizure is the phenomenologic event characteristic of epilepsy; it can be either a SYMPTOM or a SIGN. Nevertheless, we may have patients with non-epileptic seizures, but we hardly will see an epileptic patient without epileptic fits! Other signs/symptoms, and therefore, different syndromes, may be present in the different forms of epilepsy (disease). For instance, West syndrome is an epileptic disorder (epilepsy=disease) characterized by infantile spasms, hipsarrhythmia, and arrested mental development (syndrome). The causes are many, including cases without an etiology. In this example we have a disease (epilepsy) presenting in a stereotyped way (syndrome).

To establish an etiology is probably the sharpest way to identify a disease. However, an etiology can not be detected in a good number of epileptic patient, akin what happens in patients with other diseases of unknown causes (e.g. multiple sclerosis, Alzheimer disease, Parkinson disease, lateral amyotrophic sclerosis, several other neurodegenerative disorders).

Epilepsy is a condition which interferes with the individual sense of health (a disease), for even in periods of relative well-being it engenders a sense of dread. As many chronic illnesses, it has a negative social connotation. This is the social consensus that has been constructed partly out of some unspecified threat to the health of well people that the sick might pose, the loss to the social group of the labor and the earnings of the sick, and the question of deceit or fraudulent use of sickness to avoid social obligations. To deny epilepsy as a disease will not probably improve the patient's view of his condition, will not change the physician's approach to the problem, and neither lessen the negative reaction of the environment to the patient.

In summary, I think most of the confusion around this issue rises from misunderstanding and misuse of different concepts and terms respectively. Syndromes, signs and symptoms are minor concepts that integrate a larger one, disease. We should not take a part for a whole!

\section{REFERENCES}

1. Filgueiras MAS. Epilepsy is not a disease. Arq Neuropsiquiatr 1994, 52: 279-282.

2. Taylor DC. Epilepsy as a chronic sickness. In Engel J Jr. Surgical treatment of the epilepsies. New York: Raven Press, 1993, p 11. 